Short Communication

\title{
High-temperature Aging Behavior of Commercial Li-Ion Batteries
}

\author{
Xiaoyi Xie, Li Wang ${ }^{*}$, Xuning Feng, Dongsheng Ren, Xiangming He ${ }^{*}$ \\ Institute of Nuclear \& New Energy Technology, Tsinghua University, Beijing 100084, China \\ "E-mail: wang-1@tsinghua.edu.cn ; hexm@tsinghua.edu.cn
}

doi: $10.20964 / 2020.05 .71$

Received: 3 Janaury 2020 / Accepted: 26 February 2020 / Published: 10 April 2020

\begin{abstract}
Herein, we report high-temperature aging behavior of commercial Li-ion batteries (LIBs) after heating at $100{ }^{\circ} \mathrm{C}$ in which environment. After thermal aging, the results reveal a capacity drop of $61.1 \%$ during initial 2 charge/discharge cycles, however, the capacity started to recover after the $2^{\text {nd }}$ cycle and became stable after $24^{\text {th }}$ cycle. In 16 charge/discharge cycles, we have observed a capacity recovery rate of $94.5 \%$. The recovery rate linearly increased during initial four charge/discharge cycles, followed by an exponential decrease. The present report demonstrates that thermal aging can be accelerated by increasing the aging temperature, which is an efficient and fast route for performance evaluation of LIBs.
\end{abstract}

Keywords: high-temperature aging; Li-ion batteries; capacity retention; capacity recovery rate

\section{$\underline{\text { FULL TEXT }}$}

(C) 2020 The Authors. Published by ESG (www.electrochemsci.org). This article is an open access article distributed under the terms and conditions of the Creative Commons Attribution license (http://creativecommons.org/licenses/by/4.0/). 